\title{
Plano de reforma do curriculo do curso de graduação em Direito.
}

\section{Oscar Barreto Filho}

Professor Titular de Direito Comercial na Faculdade de Direito da Universidade de São Paulo.

1. Coloca-se novamente em pauta o plano de reforma do currículo da Faculdade de Direito da Universidade de São Paulo, em face da recente Resolução n. ${ }^{\circ}$ 03-72, do Conselho Federal de Educação, publicado no Diário Oficial de 26 de julho de 1972, que aprovou o currículo mínimo do curso de graduação em Direito.

São, pelo Conselho, consideradas indispensáveis à formação jurídica, as seguintes matérias:

A. Básicas

1. Introdução ao Estudo do Direito.

2. Economia .

3. Sociologia.

B. Profissionais

4 Direito Constitucional (Teoria do Estado-Sistema Constitucional Brasileiro) .

5 Direito Civil (Parte Geral-Obrigações, Parte Geral e Parte Especial-Coisas-Família-Sucessão) .

6. Direito Penal (Parte Geral - Parte Especial) .

7 Direito Comercial (Comerciantes-Sociedades-Títulos de Crédito - Contratos Mercantis e Falências) . 
8 Direito do Trabalho (Relação de Trabalho-Contrato de Trabalho-Processo Trabalhista) .

9 Direito Administrativo (Poderes AdministrativosAtos e Contratos Administrativos-Controle de Administração Pública-Função Pública) .

10 Direito Processual Civil (Teoria Geral-Organização Judiciária-Ações-Recursos-Execução)

11 Direito Processual Penal (Tipos de ProcedimentoRecursos-Execução)

12/13. Duas opcionais dentre as seguintes

a) Direito Internacional Público.

b) Direito Internacional Privado.

c) Ciência das Finanças e Direito Financeiro (Tributário e Fiscal)

d) Direito da Navegação (Marítima)

e) Direito Romano.

f) Direito Agrário.

g) Direito Previdenciário.

h) Medicina Legal.

Exigem-se também: sionado.

a) a Prática Forense, sob a forma de estágio supervi-

b) O Estudo de Problemas Brasileiros.

c) e a prática de Educação Física, com predominância desportiva de acôrdo com a legislação específica.

Estabelece ainda a Resolução n. ${ }^{\circ}$ 03-72 que o curso de Direito será ministrado no mínimo de 2.700 horas de atividades, cuja integralização se fará em pelo menos quatro e no máximo sete anos letivos.

Além da habilitação geral prescrita em lei, as instituições 
poderăo criar habilitações específicas, mediante intensificação de estudos em áreas correspondentes às matérias fixadas na Resolução e em outras que sejam indicadas nos currículos plenos.

A habilitação geral constará do anverso do diploma e as habilitações específicas, não mais de duas de cada.vez, serão designadas no verso, podendo assim o diplomado completar estudos para obtenção de novas habilitações.

Os mínimos de conteúdo e duração, fixados na Resolução, serão obrigatórios a partir de 1973.

2. Desde maio de 1968 a complexa questão da refor mulação do currículo jurídico vem sendo estudada nesta $\mathrm{Fa}$ culdade, tendo vários professores oferecido contribuições para o encaminhamento do assunto, dentre as quais se destacam os valiosos trabalhos apresentados pelos eminentes Professores Miguel Reale e A. F Cesarino Júnior, que abarcam a matéria de maneira global e exaustiva.

Como base de estudos, adotamos o plano de reorganização de ensino jurídico elaborado pelo Professor Miguel REALE, procurando adaptá-lo às imposições da mencionada Resolução n. ${ }^{\circ}$ 03-72.

Nota-se, de início, que a Resolução discrimina as matérias em "obrigatórias" (por sua vez subdivididas em "básicas" e "profissionais") e "opcionais" Permite, além disso, que, além da habilitação geral em Direito, decorrente do preenchimento do currículo mínimo, a Faculdade crie habilitações específicas (especializações), mediante intensificação de estudos nas áreas correspondentes.

Esta estruturação possibilita a adoção, nos cursos jurídicos, de currículo semi-flexível, como vem preconizado no plano de reforma sugerido pelo Professor Miguel Reale.

A par das matérias que visam precipuamente à formação profissional do advogado, são previstas algumas matérias 
básicas, de caráter geral, que têm por objetivo preparar o bacharel para a sua missão e melhor integrá-lo na comunidade.

Isto sem prejuízo das matérias práticas (Prática Forense, Problemas Brasileiros e Educação Física) que deverão obrigatoriamente completar o currículo.

3. Retomando as palavras do Professor Miguel Reale, "básicos denomino aquelas disciplinas que se destinam a fornecer ao estudante de Direito conhecimentos indispensáveis a situar a sua atividade profissional no contexto da vida social, preparando-o não só para ser advogado, promotor público, juiz, diplomata, político, ou jurisconsulto, mas, também para tornar-se um cidadão capaz de participar, com valôres próprios, da existência da comunidade"

Se acrescentarmos às existentes no atual currículo as novas matérias previstas na Resolução n. ${ }^{0}$ 03-72, serão as seguintes as disciplinas básicas:

1 Introdução ao Estudo do Direito

2 Economia (Introdução à Economia e Direito Econômico)

3. Sociologia (Introdução à Sociologia e Sociologia Jurídica)

4 Teoria do Estado

5. Direito Romano

6. Filosofia do Direito

Na disciplina de Introdução ao Estudo do Direito, serão ministradas noções sobre a posição da Ciência do Direito, a Metodologia Jurídica e as categorias fundamentais do Direito.

O Professor de Economia terá a seu cargo a introdução econômica ao estudo do Direito, completando-a com a exposição do Direito Econômico, entendido como a disciplina jurídica da produção, da circulação e da distribuição dos bens econômicos. 
Por sua vez, o Professor de Sociologia incumbir-se-á de expor noções de Sociologia Geral e, especificamente, de Sociologia Jurídica.

$\mathrm{Na}$ disciplina de Teoria do Estado, serão estudados os conceitos básicos de Ciência Política e analisados os princi. pais problemas do Estado.

A matéria de Direito Romano compreenderá a exposição sucinta das instituições do Direito Romano Privado, que tenham influenciado o direito positivo brasileiro.

Por fim, a Filosofia do Direito será o coroamento natural do curso, com o estudo da matéria filosófica referida a exemplos tirados da experiência jurídica.

Completado o ciclo básico, deverá o estudante estar ambientado no espírito da Ciência do Direito, o que será o ponto de partida para o estudo pormenorizado de cada disciplina jurídica.

4 As matérias institucionais são "as disciplinas jurídicas essenciais a todo e qualquer bacharel em Direito, qualquer que venha a ser o ramo de sua atividade profissional" (M. Reale)

Constituem, por assim dizer, o cerne do currículo jurídico e normalmente integram a formação profissional do jurista. Vêm elas indicadas, na Resolução n. ${ }^{\circ}$ 03-72, como matériasi obrigatórias, de caráter profissional.

Para completar o ciclo institucional, atendendo precipuamente ao interêsse profissional do jurista; propõe-se que, dentre as matérias opcionais enumeradas na Resolução n. ${ }^{\circ}$ 03-72, sejam escolhidas o Direito Internacional (Público e Privado), o Direito Tributário e a Medicina Legal.

As disciplinas ditas institucionais devem ser expostas da maneira compreensiva, e não extensiva, sem a preocupação de desenvolver analiticamente todo o quadro da matéria. 


\section{Como diz o Professor Miguel Reale:}

"Nada mais contrário à compreensão atual da formaçã̉o universitária do que o aprendizado em extensão, quando, na realidade, o que importa é a assimilação dos princípios informadores de cada disciplina, de seus métodos e estruturas, bem como de sua projeção como instrumento da praxis forense, administrativa, etc.

A essa luz é que se propõe uma alteração de fundo, não apenas na ordenação do currículo mas, o que é mais decisivo, na maneira mesma de situar a problemática do ensino jurídico, optando-se por uma formação de natureza institucional.

O estudante não seguirá, por conseguinte, os "pontos" de um programa minuciosamente desenvolvido, mas participará antes, atravéz de aulas teóricas e de seminários, os quais comporão uma unidade integrada indecomponível, de um curso de caráter institucional, isto é, destinado ao conhecimento teórico-prático das estruturas de cada setor da ciência jurídica, dando-se relêvo a determinados "institutos" fundamentais, tomados como "modelos" de um aprendizado concreto da matéria.

Com a adoção desse critério, será possível diminuir os períodos letivos de cada matéria, e, conseqüentemente, obter a concentração do ciclo institucional em seis semestres, desdobrados do segundo ao quarto anos."

5. Verifica-se, do exame da Resolução n. ${ }^{\circ}$ 03-72, que ela possibilita a criação de habilitações específicas, a par da habilitação geral. Em outras palavras, admite a intensificação de estudos em áreas especializadas do currículo jurídico.

Deve ser afastada a idéia de "especialização precoce" porque mutilaria a formação integral do bacharel. Não se concebe que alguém possa ser penalista ou internacionalista, sem que conheça os institutos básicos dos demais ramos da ciência jurídica.

Nada obsta, contudo, que se destine o último ano do 
curso às matérias que melhor correspondem à vocação do aluno, possibilitando-lhe a escolha entre várias opções.

O elenco das matérias especializadas seria composto pelas disciplinas opcionais mencionadas na Resolução n. ${ }^{0}$ 03-72, acrescidas de outras matérias complementares das disciplinas ditas profissionais. Nas matérias complementares, dever-se-á dar especial relevo à participação ativa do aluno, mediante o exame de problemas e casos de ordem prática.

6. Por outro lado, a atual estrutura administrativa da Faculdade de Direito, bem como a falta de pessoal docente em número adequado, impossibilita a adoção imediata de um currículo flexível, composto desde o início do curso por matérias obrigatórias e opcionais, ou, ainda eletivas (estas escoIhidas dentre as que integram os currículos de outros institutos da Universidade)

Nos Estados Unidos, por exemplo, após a conclusão do ciclo básico (college), o ciclo profissional das Escolas de Direito compreende três anos, dos quais o primeiro e o segundo semestres são formados por matérias obrigatórias e duas matérias opcionais; os quatro semestres restantes são compostos unicamente por matérias escolhidas pelo aluno, dentre o elenco das disciplinas disponíveis, de modo a totalizar certo número de créditos.

Daí a idéia de introduzir em nossa Faculdade, como primeiro passo, o currículo semi-flexível, possibilitando-se, nos dois últimos semestres a escolha, pelos estudantes, dos assuntos pertinentes ao ramo da atividade profissional de sua preferência.

As disciplinas integrantes de cada uma das 5 áreas de estudo do ciclo de especialização, seriam as indicadas como opcionais na Resolução n. ${ }^{\circ}$ 03-72, e, ainda, as matérias complementares indicadas pelos Departamentos, sob coordenação do Conselho Interdepartamental, de modo a totalizar de 10 a 12 matérias semestrais para cada secção. 
7 As 5 áreas de especialização, considerando a conveniência de se dar cunho mais profissional ao currículo, seriam, em princípio, estruturadas da forma seguinte:

Área I - Administração Pública e Financeira, para os alunos interessados nestas carreiras, ou que se destinem à diplomacia, à política ou à advocacia do Estado.

Área II - Direito Penal e Criminologia, para os estudan. tes destinados à Magistratura, ao Ministério Público, à advocacia criminal ou à administração penitenciária.

Área III - Direito e Processo Civil, para preparar os candidatos a juízes, curadores, advogados do civel.

Área IV - Administração Empresarial e Tributária, para os candidatos a estas carreiras ou à advocacia de emprêsa.

Área V - Direito do Trabalho e da Segurança Social, visando ao preparo dos futuros membros da Justiça e do Ministério Público do Trabalho e advogados trabalhistas.

As disciplinas integrantes de cada área serão, como se disse, indicadas pelos Departamentos, levando-se em conta, precipuamente, a disponibilidade de pessoal docente, ben como a possível aplicação prática dos ensinamentos recebidos, ou a sua necessidade como embasamento do curso.

As matérias integrantes do ciclo de especialização terão como pré-requisitos todas as disciplinas do ciclo institucional.

8. Justificada dessa forma a estrutura do novo currículo jurídico, em 5 anos, desdobrar-se-ia o mesmo em três ciclos:

a) ciclo básico, de formação cultural (2 semestres)

b) ciclo institucional, de formação profissional geral (6 semestres)

c) ciclo de especialização, de formação profissional especializada (2 semestres)

Observe-se que, no conjunto, para a graduação em Direito continuam a ser exigidos 10 semestres de estudos, e que, 
na área especializada escolhida pelo estudante, haverá a integração e mesmo superação da atual carga horária das disciplinas que a compõem.

No primeiro semestre de cada disciplina institucional, deverá ser dada ênfase à teoria geral, destinando-se os semestres seguintes ao estudo das partes especiais do programa.

Os programas aprovados pelos Departamentos deverão ser comunicados ao C.I.D., ao qual caberá coordenar as atividades departamentais, a fim de evitar repetições desnecessárias de matérias.

Para cada matéria, será fixado um certo número de aulas semanais, distinguindo-se entre aulas teóricas e aulas práticas. A carga horária, atribuida a cada disciplina, será closada em aulas teóricas e práticas, ou teórico-práticas, de acordo com as necessidades do desenvolvimento do curso, conforme fôr estabelecido pelo Departamento respectivo. 24 horas.

A carga semanal horária, para todos os ciclos, será de

Incumbirá, ainda, aos Departamentos fixar os pré-requisitos para matrícula nas várias disciplinas, recomendando-se, porém, que essa indicação não seja feita de modo excessivamente rigoroso, o que acarretaria indesejável retôrno ao regime do currículo rígido

9 Em consonância com a Resolução n. ${ }^{\circ}$ 03/72, o novo currículo deverá ser implantado na Faculdade de Direito a partir do próxima ano letivo de 1973.

Tendo em vista a premência do assunto, permitimo-nos sugerir o imediato encaminhamento do presente relatório aos membros da Colenda Congregação, marcando-se prazo para o oferecimento de sugestões.

O novo currículo deverá ser implantado em 1973 até o $4 .^{\circ}$ ano (VIII semestre), fazendo-se mister apenas algumas 
adaptações para que os atuais estudantes possam atingir o nível previsto na nova estrutura curricular

Caberá aos Departamentos formular indicações sobre as adaptações julgadas indispensáveis, porém, desde logo, observamos que os alunos do $3 .^{\circ}$ ano ( $\mathrm{V}$ e VI semestres) e do $4 .^{\circ}$ ano (VII e VIII semestres) deverão intensificar o estudo do Direito Processual, pois esta matéria, no currículo ora proposto, começará a ser prelecionada no $2 .^{\circ}$ ano (III semestre)

Os atuais alunos do $4 .^{\circ}$ ano terminarão normalmente o curso de graduação frequentando as matérias do $5 .^{\circ}$ ano de acôrdo com o programa vigente até agora. Somente a partir de 1974 serão feitas as opções para as 5 áreas do curso de especialização.

Não é possível adotar imediatamente o novo regime escolar tambem para os dois últimos semestres, porque as matérias obrigatórias que atualmente constam no $5^{\circ}$ ano ainda não foram ministradas aos atuais alunos do $4 .^{\circ}$ ano .

10. Ao elaborar este relatório, não perdemos de vista a atual estrutura do ensino da Faculdade, e procuramos preservar na medida do possível os altos interêsses, que reconhecemos válidos, de professores e alunos.

Torna-se claro, contudo, que a projetada reformulação conduz, necessariamente, ao encurtamento da duração de várias disciplinas até aqui consideradas obrigatórias, mas cuja extensão será amplamente compensada nos cursos opcionais nos 2 semestres derradeiros.

$\mathrm{O}$ assunto deve ser apreciado globalmente, em função dos interêsses gerais do ensino jurídico; e não à luz de considerações particulares que, evidentemente, não podem prevalecer. Em caso contrário, será inócua qualquer tentativa de reforma.

A reorganização proposta, em seus lineamentos gerais, já é conhecida por todos os membros da Casa, e, já em 1970, há dois anos, recebera parecer favorável dos membros da 
Comissão designada pela Congregação para opinar a respeito, composta pelos Professores Ruy Barbosa Nogueira, Oscar Barreto Filho e José Cretella Júnior

11 De acordo com o espírito da reforma universitária, entre as matérias do ciclo suplementar, cuja escolha caberia aos estudantes, deveriam figurar as chamadas disciplinas eletivas, a saber, aquelas ministradas em áreas afins de outros institutos da Universidade, como, por exemplo, Sociologia, Economia, Política, Psicologia, Antropologia Social, História, etc.

No entanto, este assunto somente poderá ser resolvido no futuro, à vista da localização da Faculdade de Direito fora do "campus" da Cidade Universitária .

12. No tocante ao estabelecimento de novos cursos (Estatuto da Universidade, art. 48), como o de Notariado, seria conveniente que a Congregação procurasse obter junto ao Conselho Superior da Magistratura, à Secretaria da Justiça e às Associações das classes interessadas, elementos para sua eventual criação e estruturação, em consonância com as reais necessidades dos serviços judiciários.

$\mathrm{Na}$ Universidade de Buenos Aires, segundo informa o Doutor Carlos Giuliano Fonrouge, as matérias e programas do Curso de Notariado são os mesmos do Curso de Advocacia, nas matérias indicadas. Parece-nos, contudo, que providência preliminar seria a audiência do Conselho Federal de Educação, para formulação do currículo mínimo do Curso de Notariado.

13. O currículo a seguir apresentado significa nova fase no processo de remodelação didática da Academia.

$\mathrm{Na}$ sua formulação final, foram consideradas as emendas oferecidas à Congregação, inclusive as sugeridas pela representação discente.

Como bem assinalou o Professor Irineu Strenger, ao justificar as emendas que apresentou: 
"I A matéria deve ser focalizada sob dois ângulos principais:

a) o que interessa ao âmbito da Universidade; Direito.

b) o que interessa ao âmbito interno da Faculdade de

2. No que concerne à letra "a", o projeto a ser encaminhado à Câmara de Graduação do CEPE deve obedecer, em linhas principais e amplas, às regras estatutárias, ou seja, as disciplinas devem ser enunciadas, apenas para efeito de composição curricular, ilustrado com um modêlo ideal de semestralização .

3 Para efeito da letra "b", cada Departamento deveria examinar a matéria em profundidade, apresentando programas e estabelecendo os requisitos, que chamamos de relativos porque dependentes do pronunciamento de cada unidade didático-administrativa interna, "ad-referendum" do Conselho Interdepartamental, ficando desde logo aprovados pela Egregia Congregação os chamados requisitos absolutos, conforme o quadro anexo.

4 Em face da Portaria GR-1380, de 01-02-1971, e correspectiva Portaria Fadusp n. ${ }^{\circ} 1 / 22$, de 3-1-1972, há um mínimo e um máximo de disciplinas que devem ser cursadas semestralmente, impondo-se uma coordenação relativamente ao esboço do currículo, embora apresente uma organização ideal, mas que, por certo, não poderá numericamente impossibilitar a conclusão do curso num período menor de cinco anos e maior de sete.

5 Manteremos, por conseguinte, o mesmo quadro do ante-projeto original, alterando algumas denominações de disciplinas, em obediência a preceitos legais e apresentando os esquemas de semestralização, para os efeitos do ítem l, letra "b"

6 Por outro lado, tomamos a liberdade de sugerir, data venia, que a parte geral de algumas disciplinas seja de- 
senvolvida como Teoria Geral, dada a importância de tal pressuposto conceitual e metódico, caracterizado na significação da análise, que parte do material do direito positivo em normas jurídicas.

O principal objetivo seria desenvolver, com base nos ordenamentos concretos, ou de peculiares setores jurídicos, os fundamentais conceitos gerais, ou seja, com os modelos dos preceitos gerais, elaborar uma teoria normativo-positiva de toclas as formas da experiência jurídica na área da disciplina em estuclo, focalizada, assim, como e enquanto ordenamento jurídico.

Preferimos, portanto, denominar, por exemplo, a disciplina Direito Civil - Parte Geral, de Teoria Geral do Direito Civil, o mesmo fazendo com as disciplinas que comportassem esta visão estrutural prévia"

\section{Currículo do Curso de Graduação em Direito.}

A. Ciclo Básico.

I. Semestre

$N .^{\circ}$ de aulas semanais

a) Introdução ao Estudo do Direito I

4

b) Sociologia

4

c) Economia I

4

d) Teoria do Estado I

4

e) Direito Romano I ....

4

f) Teoria Geral do Direito Civil I 4 


\section{Semestre}

a) Introdução ao Estudo do Direito II . . 4

b) Sociologia Jurídica $\quad$. 4

c) Economia II $\quad$. . . . . 4

d) Teoria do Estado II 4

f) Direito Romano II . . . . . $\quad 4$

g) Teoria Geral do Direito Civil II 4

B. Ciclo Institucional.

III Semestre

a) Direito Civil I (Parte Especial: Obrigações)

b) Teoria Geral do Direito Comercial 5

c) Teoria Geral do Direito Penal I 5

d) Teoria Geral do Direito Constitucional. 5

e) Teoria Geral do Processo I . . 5

\section{Semestre}

a) Direito Civil II (Parte Especial: Contratos)

b) Direito Comercial I (Parte Especial) : 5

c) Teoria Geral do Direito Penal II .. 5

d) Direito Constitucional (Sistema Constitucional Brasileiro)

e) Teoria Geral do Processo II .. . 4

f) Estudo de Problemas Brasileiros . 2 


\section{Semestre}

a) Direito Civil III (Parte Especial: Direitos Reais)

b) Direito Comercial II (Parte Especial) .. 4

c) Direito Penal I (Parte Especial) .. $\quad$. 4

d) Direito do Trabalho I 3

e) Direito Financeiro .... ... 4

f) Direito Processual Civil I (Parte Especial) 4

\section{Semestre}

a) Direito Civil IV (Parte Especial: Direito de Família)

b) Direito Comercial III (Parte Especial) .. 4

c) Direito Penal II (Parte Especial) .. 4

d) Direito do Trabalho II .. 3

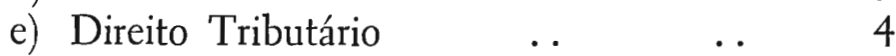

f) Direito Processual Civil II (Parte Especial) 4

\section{Semestre}

a) Direito Civil V (Parte Especial: Direito da Sucessão)

b) Direito Processual Civil III (Parte Especial)

c) Direito Processual Penal I

d) Teoria Geral do Direito Administrativo.

e) Teoria Geral do Direito Internacional Público

f) Filosofia do Direito (Parte Geral) .. 3 


\section{Semestre}

a) Direito Processual Civil IV (Parte Especial) . . . . . . . $\quad . \quad 5$

b) Direito Processual Penal II $\quad \ldots \quad \ldots \quad 4$

c) Direito Administrativo: Parte Especial. 3

d) Teoria Geral do Direito Internacional Privado $\quad$.. . . .... 4

e) Filosofia do Direito: Parte Especial . 3

f) Medicina Forense . . . . . 5

Observações:

$1 .^{a}$ - O número previsto de aulas semanais visa permitir o estudo intensivo das disciplinas jurídicas básicas, dosando-se as aulas em teóricas e práticas, na medida da disponibilidade de docentes e do desenvolvimento do curso, a critério dos respectivos Departamentos.

2. ${ }^{\text {a }}$ - No estudo das partes especiais, cada Departamento distribuirá os assuntos, tend.o em vista as opções previstas para os dois últimos semestres, bem como resolverá sobre a conveniência de o professor acompanhar ou não a turma até concluir o estudo da disciplina.

3. a - Nas disciplinas de Direito Processual (V a VIII semestres), serão organizados exercícios de Prática Forense, sob a forma de estágio supervisionado.

\section{Ciclo de Especialização \\ IX e X Semestres}

Ārea I - Direito Político, Administrativo e Financeiro

(Mínimo de 22 horas semanais)

Ciência da Administração (Problemas Jurídicos) 
Ciência das Finanças (Problemas Jurídicos)

Direito Administrativo Aplicado

Direito Financeiro Aplicado

Direito Tributário Aplicado

Direito Econômico

Direito Internacional Público (Parte Especial)

Direito Eleitoral e Partidário

Organizaçōes Internacionais

Política Internacional

Relações Intergovernamentais

Direito Diplomático

Direito de Telecomunicações

Liberdades Públicas

Direito Municipal

Direito Constitucional Estadual

Área II - Direito Penal e Criminologia

(Mínimo de 22 horas semanais)

Direito Penal Complementar

Criminologia

Medicina Forense

Psicologia Judiciária

Direito Penal Militar

Sistemas Penitenciários

Prática do Processo Penal

Direito Penal Fiscal

Direito Penal Econômico

Oratória Forense e Prática do Juri

Área III - Direito Privado e Processo Civil

(Mínimo de 22 horas semanais)

Direito Civil Aplicado

Direito Comercial Aplicado

Direito Internacional Privado Aplicado

Direito Agrário

Direito de Autor

Direito Falimentar 
Prática de Processo Civil Processos Especiais

$$
\begin{aligned}
& \text { Área IV - Direito de Emprêsa } \\
& \text { (Mínimo de } 22 \text { horas semanais) }
\end{aligned}
$$

Direito Comercial Aplicado

Direito Tributário Aplicado

Direito Econômico Aplicado

Direito Falimentar

Direito Internacional Privado Aplicado

Direito da Navegação Marítima e Aeronáutica

Direito Industrial

Direito Bancário

Direito de Seguros

Prática de Processo Civil

$$
\begin{aligned}
& \text { Área V - Direito do Trabalho } \\
& \text { (Mínimo de } 22 \text { horas semanais) }
\end{aligned}
$$

Direito do Trabalho Aplicado

Teoria Geral da Segurança Social

Direito Processual do Trabalho

Direito Coletivo do Trabalho

Direito Previdencial

Direito Prevencionista e Infortunístico

Prática do Processo Trabalhista

\section{Observações:}

1. ${ }^{\text {a }}$ O ciclo de especialização terá sentido integrado, ao mesmo tempo teórico-prático, devendo os assuntos ser tratados sob a forma de problemas e estudo de casos concretos.

$2 .^{\mathrm{a}}$ - A indicação das disciplinas integrantes do ciclo de especialização é meramente exemplificativa, cabendo aos Departamentos interessados definir as matérias a ser ministradas nas diversas áreas, e ao Conselho Interdepartamental a coordenação dos programas e fixação das respectivas cargas horárias. 
3. ${ }^{a}$ - Caberá ao aluno indicar, no início do IX semestre letivo, a área de estudos que pretende seguir. A discriminação das 5 áreas não é rígida, e, desde que haja compatibilidade de horário, poderá o estudante de uma área optar por até três disciplinas de áreas distintas, de modo a completar o mínimo de 22 horas semanais. 